\title{
ENTRE APROXIMAÇÕES E RUPTURAS: AS GUINADAS NA INTEGRAÇÃO REGIONAL
}

\author{
Luiz Felipe Brandão Osório'
}

\begin{abstract}
A integração regional flutua no plano das ideias entre Bolívar e Monroe. Com aproximações e rupturas, a concretização da cooperação ocorre dentro das margens concedidas pela economia política liberal, o chão dos processos integracionistas. Dentro dessa dinâmica, a política externa brasileira sofreu recentemente mais uma brusca correção de rumos. A partir de 2016, a preocupação da chancelaria brasileira passa a ser desfazer o que havia sido feito pela anterior. A ruptura com o modelo vigente até então evidencia o resgate de uma postura de alinhamento automático, associativa às grandes potências ocidentais, como os Estados Unidos e sua esfera de aliados, em detrimento da autonomia e do pragmatismo de outrora. Com a nova orientação, novos foros de integração emergem, como o Fórum para o Progresso e Desenvolvimento da América do Sul (PROSUL), enquanto outros decaem, como a União de Nações Sul-Americanas (UNASUL), e outros, ainda, são redirecionados, como o Mercado Comum do Sul (Mercosul). A mudança ocorre em um contexto internacional de crise econômica e de um nítido acirramento das tensões geopolíticas em torno da disputa pela hegemonia. Em função disso, este artigo tem dois objetivos: um mais amplo, que é fundamentar a política externa brasileira de acordo com o panorama atual do capitalismo, aquele do pós-Guerra Fria, do pós-fordismo; e dentro desse universo, um mais específico, o de apontar as transformações ocorridas em termos de integração regional (grande questão do pós-1991). Por meio da ferramenta da teoria materialista do Estado pretende-se dissipar as aparências para se chegar à essência do fenômeno da política externa para integração regional no capitalismo.
\end{abstract}

Palavras-chave: integração regional; organização internacional; capitalismo; política externa; desenvolvimento.

\section{BETWEEN RAPPROCHMENTS AND RUPTURES: TURNS IN REGIONAL INTEGRATION}

Regional integration fluctuates in terms of ideas between Bolívar and Monroe. With rapprochements and ruptures, cooperation occurs within the margins provided by the liberal political economy, the ground of integrationist processes. Within this dynamic, Brazilian foreign policy has currently undergone another sharp correction. From 2016 onwards, the concern of the Brazilian chancellery was to undo what had been done by the previous one. The rupture with the model prevailing until then demonstrates the recovery of an automatic alignment behavior, associated to the great Western powers, such as the United States and its sphere of influence, to the detriment of the autonomy and pragmatism of previous administrations. In this new context, new forums for integration have emerged, such as Forum for the Progress of South America (PROSUR), while others have declined, such as Union of South American Nations (UNASUR), and yet others have been redirected, such as Southern Common Market (MERCOSUR). These changes take place in an international context of economic crisis and an evident sharp increase in geopolitical tensions

\footnotetext{
1. Professor de direito e relações internacionais e coordenador do curso de relações internacionais na Universidade Federal Rural do Rio de Janeiro (UFRRJ); autor do livro Imperialismo, Estado e Relações Internacionais, de 2018, pela Editora Ideias \& Letras; e mestre e doutor em economia política internacional pela Universidade Federal do Rio de Janeiro (UFRJ). Orcid: <http://orcid.org/0000-0001-6058-7809>
} 
regarding the dispute for hegemony. Therefore, this article has two objectives: a broader one, which is to relate Brazilian foreign policy to the current panorama of capitalism (post-Cold War and post-Fordism), and a more specific one, within this scope, to point out the transformations that have occurred in terms of regional integration since 1991. From the perspective of the materialist theory of the State, the article aims to dispel appearances in order to arrive at the essence of the phenomenon of foreign policy for regional integration in capitalism.

Keywords: regional integration; international organization; capitalism; foreign policy; development.

\section{ENTRE ACERCAMIENTOS Y RUPTURAS: LOS GIROS EN LA INTEGRACIÓN REGIONAL}

La integración regional fluctúa en el plano de las ideas entre Bolívar y Monroe. Con aproximaciones y rupturas, la concretización de la cooperación ocurre dentro de los márgenes otorgados por la economía política liberal, la base de los procesos integracionistas. Dentro de esta dinámica, la política exterior brasileña ha experimentado otra fuerte corrección en su orientación. A partir de 2016, la preocupación de la cancillería brasileña ha sido deshacer lo que se hizo anteriormente. La ruptura con el modelo vigente hasta entonces, muestra la recuperación de una postura de alineación automática, en relación a las grandes potencias occidentales, como los Estados Unidos y su esfera de aliados, en detrimento de la autonomía y el pragmatismo del pasado. Bajo esta nueva dirección, surgen nuevos foros para la integración, como Foro para el Progreso y Desarrollo de América del Sur (PROSUR), mientras que otros disminuyen, como Unión de Naciones Suramericanas (UNASUR), y otros son redirigidos, como Mercado Común del Sur (Mercosur). El cambio tiene lugar en un contexto internacional de crisis económica y un fuerte aumento de las tensiones geopolíticas que rodean la disputa por la hegemonía. Por ese motivo, el presente artículo tiene dos objetivos: uno más amplio, que es fundamentar la política exterior brasileña en el panorama actual del capitalismo, de la posguerra fría, de posfordismo y, dentro de este campo de análisis, uno más específico, que busca señalar las transformaciones que han tenido lugar en el área de la integración regional (un gran problema a partir de 1991). A través de la teoría materialista del Estado, se pretende disipar las apariencias para llegar a la esencia del fenómeno de la política exterior para la integración regional en el capitalismo.

Palabras clave: integración regional; organización internacional; capitalismo; política externa; desarrollo.

JEL: F53.

DOI: http://dx.doi.org/10.38116/rtm23art7

Data de envio do artigo: 16/4/2020; Data de aceite: 26/8/2020.

\section{INTRODUÇÃO}

Falar em integração regional, pelo viés científico das relaçóes internacionais, demanda precisão teórica e demarcação temporal e espacial para que não nos percamos em retrocessos ad infinitum. É preciso, portanto, ir muito além da União Ibérica ou do Pacto Colonial, como também é importante superar momentos ainda incipientes e muito vinculados a singularidades e náo a um todo sistêmico, como no período das descolonizaçóes americanas. Tanto a Doutrina Monroe quanto as ideias de unidade de Bolívar estiveram muito atreladas a projetos específicos de poder na região, em um momento em que o capitalismo 
ainda não era um modo de produção predominante mundialmente e que os Estados-nação ainda não haviam se consolidado plenamente na porção meridional. Seria possível ainda pinçar exemplos pioneiros, isolados no tempo, como o Pacto ABC (Argentina, Brasil e Chile), ${ }^{2}$ o qual, para muitos, é o embrião da integração no Cone Sul. Há ainda, no sul e no centro da América, algumas iniciativas esparsas que poderiam também ser citadas.

O fundamental para este artigo é demarcar o tempo e o espaço da integração regional na América do Sul como um fenômeno próprio de um sistema de Estados, o qual se concretiza a partir da chegada das relaçóes de produção capitalistas nos Estados-nação da região, ou seja, quando o capitalismo se torna o modo de produção predominante nessas localidades e, consequentemente, em todo o mundo. Nessa linha, o marco temporal é o pós-1945 (com a respectiva inflexão no pós-1991), período em que o capitalismo irrompe de fato na América Latina, com os projetos de industrialização, o deslocamento o eixo agrário para o urbano das economias nacionais e as demandas por desenvolvimento socioeconômico, esgarçando de vez as relaçóes sociais nos países. O espaço, por sua vez, é o da América Latina, em meio ao sistema capitalista de Estados, que desde o período pós-Segunda Guerra Mundial já alcançava todos os quadrantes do globo e se moldava nos mesmos parâmetros estruturais que se seguem até os dias atuais, clivado entre centro e periferia.

A partir da reconfiguraçáo do mundo e do capitalismo, com a hegemonia estadunidense, é possível desenhar um arco que uniformiza, ainda que em alguns casos tangencialmente, as iniciativas de integração regional, inserindo-as em uma mesma lógica sistêmica (capitalista), não obstante as diferenciaçôes locais de orientação conjuntural político-econômica. Como o nosso foco é o Brasil, terão relevo as iniciativas de integração regional tanto econômicas quanto políticas nas quais o país se engajou, sendo o tempo o pós-1945 e o espaço a América do Sul.

Cabe, aqui, traçar uma linha que costura o histórico da integração regional até chegarmos aos dias atuais e, naturalmente, à mais recente guinada da política exterior para o continente. Por ser um assunto importante, a diretriz da política exterior dos candidatos já estava definida desde os primeiros debates da corrida eleitoral brasileira. Desse modo, o resultado atual, de desconstrução de parte significativa dos arranjos feitos nos governos Lula e Dilma e de retomada das diretrizes da era Fernando Henrique Cardoso não foi surpresa para os

2. Oficialmente nomeado Pacto de não Agressão, Consulta e Arbitragem, o acordo foi celebrado em 1915 e ganhou o acrônimo $A B C$ em função da letra inicial de seus membros. 0 tratado ficou marcado por ser um arroubo de autonomia em meio a um contexto de dominância estadunidense, articulando no Cone Sul estratégias e iniciativas importantes de fortalecimento da posição externa dos países envolvidos (entre os dispositivos havia a previsão da cooperação militar na região). Embora de cunho inovador, a iniciativa não galgou grandes êxitos, a não ser o impacto momentâneo. A aliança tentou ser reanimada na década de 1950, mas sem muita repercussão. 
internacionalistas. A integração regional não ficou à margem dessa correção de rumos. As iniciativas mais recentes denotam claramente a nova tendência, que não se restringe à mudança do governo brasileiro. Se o Mercado Comum do Sul (Mercosul) manteve-se, com redirecionamentos substanciais em seu foco e sua atuação, a União das Nações Sul-Americanas (UNASUL) foi implodida. Em seu lugar, vieram com mais força o Fórum para o Progresso da América do Sul (PROSUL) e o Grupo de Lima. Os dois projetos, por serem mais ilustrativos desse movimento à direita, mereceráo maior destaque. Para discorrer sobre o tema, anelando-o no contexto mais amplo do sistema capitalista de Estados, é fundamental perpassar uma sistemática de interfaces entre os aspectos mundiais do capitalismo e as questóes mais locais dos processos de integração regional.

Nesse diapasão, este texto estrutura-se em: $i$ ) uma contextualização e explicação do período histórico do sistema de Estados no pós-1945, dentro da dinâmica do capitalismo fordista; ii) um breve panorama regional das iniciativas empreendidas até a década de 1990; iii) a apresentação das transformaçôes no capitalismo no pós-1991, pós-Guerra Fria, passando para o momento pós-fordista; e iv) uma análise dos impactos na América do Sul e suas consequentes reconfiguraçóes e expansôes. Por fim, na última seção é dada maior atenção às observaçôes e aos comentários sobre o PROSUL, o Grupo de Lima e a política externa brasileira atual, sua confrontação à UNASUL e à política externa regional de governos anteriores.

\section{A INTEGRAÇÃO REGIONAL NO PÓS-1945}

$\mathrm{O}$ termo integração regional está intimamente vinculado ao momento do pós-Segunda Guerra Mundial em meio à hegemonia ${ }^{3}$ estadunidense, manifestada pelas instituições - organizações internacionais como Organização das Nações Unidas (ONU), Organização do Tratado do Atlântico Norte (Otan), Fundo Monetário Internacional (FMI)/Banco Internacional de Reconstrução e Desenvolvimento (Bird) - e por práticas - como o american way of life, o welfare state e a definição do dólar estadunidense como moeda de referência internacional. Foi quando as relaçóes de produção capitalistas saem do eixo continental europeu e tomam (predominantemente) todos os quadrantes do mapa-múndi. ${ }^{4}$ Os processos de industrialização nas Américas e de descolonização na África e na Ásia, por exemplo, são sinais de que o capitalismo já esgarçava as relaçōes sociais mundo afora. Nesse sentido, o abrangente termo integração regional ganha especificidade. Em outras palavras, o conceito passa a ser atravessado pela economia política. Não fortuitamente, esse é seu pano de fundo. Integração regional fala de economia política, do capitalismo como modo de produçáo dominante no sistema de Estados.

3. O conceito de hegemonia adotado aproxima-se daquele exposto por Poulantzas (1969).

4. Mais informações em Osorio (2015; 2018). 
Além da especificidade dada pelo capitalismo, há a peculiaridade do arranjo político que a conforma. O regionalismo incentivado do pós-Segunda Guerra Mundial é o da economia política liberal. Ou seja, passam a ser louvadas as articulações regionais em torno de um mesmo objetivo: a formação de um livre mercado comum, um espaço de liberdades econômicas em contraposição ao território nacional, âmbito da intervenção estatal. Essa liberdade pode ser mitigada em maior ou menor medida, a depender do espectro político de sua condução. Se por partidos de esquerda, mais intervencionista, limitando mais os capitais; se por grupos de direita, menos, dando maior liberdade econômica aos capitais. O que permanece desde sua origem é a busca do fim: o mercado livre e comum, que se concretiza pelo apoio do Estado e de políticas públicas ou ao sabor das forças de mercado.

Em função de todas as condicionantes internacionais (Revolução Russa, crise de 1929, destruição da Europa Ocidental e New Deal), o capitalismo reconfigurou-se em uma versão fordista, ${ }^{5}$ voltada para a acumulação interna e para a regulação nacional-estatal pela via do Estado de bem-estar social. Impossibilitado de prosperar no contexto interno, o livre mercado comum passou, então, a ser buscado e constituído no plano externo. Veio, assim, o experimento pioneiro europeu, que serviria de espelho para iniciativas pelo mundo. Para Anderson (2012), a Europa Ocidental foi um laboratório de experiências do liberalismo econômico internacional - e ainda o é -, contando com a chancela estadunidense, de modo a servir de modelo ou de exemplo para as outras regióes do globo.

Após a Segunda Guerra, o fordismo foi universalizado, constituindo não apenas uma forma econômica de organização mas um amplo modelo social que impactou diversas searas da sociedade moderna. A articulação do padrão de desenvolvimento ocorreu em torno de um regime de acumulação interno, intensivo, com produção e consumo de massa, buscando incremento tecnológico, crescimento e estabilidade, além de um modo de regulação nacional-intervencionista, baseado no constante dirigismo estatal, capaz de criar apaziguamentos políticos e uma ampla rede de proteção social (Jessop, 1991).

O fordismo penetrou substancialmente em todos os processos econômicos, as estruturas de classe, os valores e os modos de vida, não apenas na parte capitalista do mundo (Hirsch, 2010). Se na fase anterior ao fordismo, a concorrência entre particulares, e o seu desenrolar em concentração e monopólios, se estabelecia

5. A origem do termo fordismo designa uma homenagem a Henry Ford, que inseriu pioneiramente a esteira rolante na montagem de automóveis. Ou seja, a definição de fordismo está em princípio atrelada à organização do trabalho industrial (Gramsci, 2008). Assim, ficavam eliminados na prática os últimos resquícios de competência artesanal no processo de trabalho industrial (Kurz, 1992). 0 termo serviu para caracterizar a produção de mercadorias aproximadamente dos anos 1920 até os 1980. A inspiração estava em Frederick Taylor (1856-1915), engenheiro por formação, que desenvolveu e publicou o livro que se tornou manual de ensino sobre direção científica de empresas, com base em princípios de especialização e racionalidade da produção. 
como padrão, nesse regime as relações capitalistas são diretamente dirigidas pelo Estado. Nesse sentido, o fordismo significou uma etapa decisiva na implementação histórica total do capitalismo, a qual contou com o decisivo apoio e engajamento dos Estados Unidos como potência hegemônica. A reorganização do mundo em torno de instituiçôes internacionais, como as organizaçôes internacionais foi uma das sínteses importantes desse processo (Mascaro, 2013).

$\mathrm{O}$ alargamento do fordismo em âmbito internacional permitiu que ele se tornasse um processo global, com implicaçóes próprias, o que é bem descrito empiricamente por Lipietz (1988). A partir de sua consolidação, pode-se traçar uma série de características estruturais gerais e tendências comuns de desenvolvimento sob seu regime de acumulação e seu modo de regulação determinados. Isso não significa dizer que houve uma uniformização dos efeitos e das incidências no fordismo pelo mundo.

Dado que a própria constituição e a dinâmica do sistema de Estados estão atreladas à desigualdade e à exploraçáo e que politicamente a esfera internacional se organiza na pluralidade de unidades fragmentadas, com relaçóes de classes e de forças singulares, os Estados nacionais conheceram modelos de crescimento e de desenvolvimento bastante díspares. Ainda que em um mesmo continente geográfico ou mesmo no centro da acumulação capitalista, os países sentiram efeitos singulares das experiências fordistas, tendo em vista os particulares arranjos internos de coesão nas searas política e social. A correlaçáo de classes e forças que impacta o regime de acumulação e o modo de regulação respectivo leva a modelos nacionais de desenvolvimento peculiares. Em outras palavras, o fordismo precisa ser compreendido em suas duas facetas: um sistema geral do capitalismo global e, ao mesmo tempo, uma experiência com modulaçóes particulares em cada Estado (e de cada região).

Como não poderia deixar de ser, a América Latina, primeiramente, e a América do Sul, posteriormente, seguiram a mesma toada, com reluzentes singularidades. Se no centro de acumulação capitalista, Estados Unidos e Europa Ocidental gozaram de índices inéditos de prosperidade, na periferia sistêmica, onde os processos de modernização capitalista ainda restavam incompletos, os ecos do fordismo foram sentidos com bem menos intensidade. O pleito principal era pela industrialização acompanhada pelo desenvolvimento econômico, isto é, partindo do mesmo ponto, mas trilhando caminhos distintos é que se constrói a trajetória da integração sul-americana.

\section{A INTEGRAÇÃO REGIONAL LATINO-AMERICANA NO FORDISMO: ASSOCIAÇÃO LATINO-AMERICANA DE LIVRE COMÉRCIO E ASSOCIAÇÃO LATINO-AMERICANA DE INTEGRAÇÃO}

Comparando a integração regional latino-americana com o projeto comunitário europeu nota-se divergências como a náo linearidade, e menor quantidade, das 
iniciativas e a posição do poder hegemônico, o qual é bem mais tolerante no centro e mais agressivo na periferia. Há, entretanto, convergências que permitem inserir os dois na mesma lógica, como o vetor econômico prioritário (a criação de um mercado comum e livre) e a dinâmica normativa que o respalda (como a similitude entre regras e instituiçóes). Dentro desse panorama, o pós-1945 é o primeiro momento do florescimento de diferentes projetos integracionistas regidos pelos mesmos parâmetros, com maior ou menor proximidade entre eles. É imperioso apontar que, nesse primeiro ato da integração, a América Latina foi o espaço abarcado, principalmente pela marcante presença do México nas iniciativas, o que não seria mais visto a partir dos anos 1990, com a mudança de orientação do país, ingressando no North American Free Trade Agreement (Nafta), quando o foco deixa de ser latino-americano e passa a ser restrito ao sul-americano. Logo, fundamental aqui serão os projetos nos quais o Brasil participa ativamente, a despeito de relevantes iniciativas americanas que não o tocam diretamente. ${ }^{6}$

Dentro desse quadro, no espaço da América Latina, podemos citar dois projetos que envolveram o Brasil e outros países vizinhos dentro de uma mesma lógica, própria do momento fordista do capitalismo: a do regionalismo fechado. Ou seja, protecionismo quanto ao mercado externo e incentivos à produção local, de modo a fomentar as economias nacionais para que formasse entre si um livre mercado comum. Sob a influência do pensamento modernizante, cepalino, pela necessidade da industrialização (para a substituição de importaçôes), a articulação regional era mais um mecanismo para promover o desenvolvimento local a fim de, a partir de patamares próximos, competir em condiçóes mais favoráveis no espaço internacional.

Nesse sentido, temos a Área de Latino-Americana de Livre Comercio (ALALC), que foi criada em Montevidéu em 1960, por meio de um tratado assinado por Brasil, Argentina, Chile, México, Paraguai, Peru e Uruguai. Foi inspirada nos ditames da Comunidade Econômica Europeia, de 1957 (Tratado de Roma), e também nas diretrizes da Comissão Econômica para a América Latina e Caribe (CEPAL), o que deixou instituição com um caráter

\footnotetext{
6. Em 1960, na América Central, foi celebrado o Mercado Comum Centro-Americano (MCCA), existente até hoje, integrando Costa Rica, Guatemala, Honduras, Nicarágua e El Salvador, com o objetivo de criar um mercado comum na região, realizado no âmbito da Organização dos Estados Centro-Americanos (ODECA). A Comunidade Andina de Nações (CAN), ou Pacto Andino, foi celebrada em 1969, contando, ao longo de sua trajetória, com Colômbia, Equador, Bolívia, Peru, Chile e Venezuela. Pensada como uma iniciativa de integração econômica, a arquitetura do bloco foi incrementada institucionalmente com a criação de alguns órgãos: uma corte, um parlamento e um conselho de ministros das relações exteriores. Na década de 1990, o pacto atinge o estágio de zona de livre comércio, inclusive com a introdução de uma tarifa externa comum. Ainda vigente, a iniciativa perdeu espaço ante projetos mais amplos dentro da América do Sul. Criada em 1973, a Comunidade e Mercado Comum do Caribe (CARICOM) tornou-se um bloco de cooperação econômica e política, visando à promoção do livre comércio, o livre trânsito de capital e trabalho e a formulação de políticas públicas comerciais e estratégias políticas comuns. Seus quinze membros são países caribenhos da América Central, como o Haiti, bem como Guiana e Suriname na América do Sul. 0 bloco possui uma área de livre comércio e boas relações com Cuba. Nos anos 2000, foi criada uma corte de justiça para resolver os conflitos locais.
} 
híbrido. Ao mesmo tempo em que buscava a concretização do livre mercado comum na região (para o qual havia um prazo estabelecido de doze anos após sua entrada em vigor), fechava-se ao mercado internacional, com uma lógica de fomento interno via protecionismo e incentivos às indústrias locais antes de se lançar à concorrência da economia mundial.

Pensava-se em um mercado comum como elemento fundamental para a materialização do processo de substituição de importaçóes e, consequentemente, como fator que atenuasse a vulnerabilidade externa. Seu funcionamento era considerado rígido pela ótica liberal, pois a concessão comercial de um país membro a outro deveria imediatamente ser estendida aos demais, respeitando a cláusula da nação mais favorecida. O notório viés desenvolvimentista (mais protecionista) que a carreou ilustrou, em alguma medida, a demanda da periferia americana por desenvolvimento na recente configuraçáo internacional, afastando-se relativamente de um pan-americanismo, mais conectado com o regime da Organização dos Estados Americanos (OEA). Apesar da entrada de novos membros na década de 1970 (Bolívia, Colômbia, Equador e Venezuela), a iniciativa não prosperou, não tendo cumprido o prazo estipulado para a efetivação do seu mercado comum, por variadas razóes, mas, sobretudo, pela mudança na orientaçẫo política dos governos e pelas transformaçôes na cena internacional.

Em 1980, a ALALC foi substituída pela Área Latino-Americana de Integração (ALADI), na mesma linha de raciocínio (desenvolvimento econômico gradual e progressivo), que pode ser cunhada como de regionalismo fechado para o mercado internacional, com vistas a superar a descontinuidade da iniciativa anterior. A ALADI emergiu, todavia, em um contexto muito distinto do anterior.

Muitas das transformaçôes que viriam a se concretizar na década de 1990 começavam a ser gestadas, com o desgaste das ditaduras civil-militares e o espectro do neoliberalismo. Em vez de predeterminar prazos e metas específicas, ela atuava como uma incubadora de iniciativas (multilaterais ou bilaterais) por meio dos acordos de complementação econômica entre seus membros, substituindo a cláusula da nação mais favorecida, pela cláusula de habilitação, que significa a não extensão automática dos benefícios comerciais. Sua flexibilidade institucional garantiu sua sobrevivência e seu ainda ativo funcionamento. Seus membros são os mesmos da ALALC, com a inclusão de Panamá e Cuba. Mais atinente às mudanças no contexto internacional, a ALADI permite que variados acordos sejam celebrados sob sua guarida, como o foi, por exemplo, o Tratado de Assunção, que criou o Mercosul.

Apesar de ser um subproduto da ALADI, o Mercosul é plenamente autônomo, constituindo-se uma iniciativa centrada em uma nova lógica, em um novo momento da configuração mundial, pós-Guerra Fria, dentro da vitória da democracia liberal estadunidense, em plena ascensão e consolidação do 
neoliberalismo no globo. Abertura de mercados, flexibilização de regras, derrubada de barreiras tarifárias: essas eram as novas palavras de ordem do momento. As iniciativas de integração regional passaram a gozar de enorme proeminência, sendo estimuladas e incentivadas. Os acordos e as coalizóes ganharam também um novo nome: blocos regionais, de maneira a ilustrar a solidez e a coesão dos membros em torno do aumento da competição e das melhores condiçôes no vasto mercado internacional. Dessa forma, o regionalismo aberto à concorrência internacional é, portanto, amplamente defendido na retórica justificadora dos processos.

\section{A INTEGRAÇÃO REGIONAL PÓS-1991}

A nova organização social que emergia, rompendo com os parâmetros fordistas, pode ser cunhada como pós-fordista, por constituir um momento de reação, de desfazimento da correlaçáo de outrora. Diferentemente do que ocorrera no período anterior, não havia uma denominação específica ligada ao modo de organização da produçáo. Em verdade, a alcunha advém da negaçáo das premissas dadas, que foi uma saída à crise do fordismo (Bonefeld e Holloway, 1991). Logo, o pós-fordismo é uma desconstrução e, simultaneamente, uma reconstruçáo dos parâmetros capitalistas. Apesar dos efeitos críticos terem sido sentidos desde pelo menos a década de 1970, é a partir do final da Guerra Fria, na aurora da década de 1990, com a dissolução das experiências socialistas no Leste Europeu, que o ciclo pós-fordista se sedimenta. Esse período marca a consolidação e difusão pelo mundo do novo regime de acumulação e do respectivo modo de regulação que tecerão a nova face do padrão de desenvolvimento do capitalismo.

Como modelo reativo, as características embasam-se na superação das peculiaridades fordistas (Jessop, 1991). O taylorismo da organização do trabalho sucumbe ao toyotismo na produçáo, ou seja, a racionalização do uso da força de trabalho, o crescimento da automação e da desconcentraçáo industrial. As transformaçóes no regime de acumulação vão nesse sentido. Pode-se afirmar que, fundamentalmente, houve um deslocamento do eixo central, que antes gravitava em torno do mercado interno, passando a se conectar ao mercado internacional. Leia-se: defesa da liberalização das regras e abertura das economias para o livre trânsito dos capitais, expandindo a sua esfera de valorização por sobre e além dos territórios nacionais. As novas tecnologias, como transportes, comunicação, biotecnologia e genética, pressionam por essa dinâmica, alterando significativamente a relação entre tempo e espaço, por exemplo.

Nessa toada, a lição fundamental é saber se livrar da armadilha da globalização. Não é ela que marca o novo regime de acumulação. O capital, em sua essência, é internacional, é inexoravelmente expansivo, global. ${ }^{7}$

7. Mais informações em Bonefeld (2013) e Braunmühl (1978). 
O diferencial desse momento foi como se manifestou a internacionalização da produção. Por meio da liberalização dos fluxos comerciais, do fim das amarras financeiras, da livre circulação dos capitais e da introdução de novas tecnologias de comunicação e transporte criou-se uma rede ampla e flexível de possibilidades de valorização, mais independentes das demandas do trabalho. O capitalismo é essencialmente, portanto, desde sempre, globalizado, no sentido de pressionar pela internacionalização da produção. $\mathrm{O}$ que diferencia o padrão pós-fordista de desenvolvimento são as condições estruturais de acumulaçấo e regulaçấo, nacionais e internacionais.

O neoliberalismo, como modo de regulação, acompanha o deslocamento do eixo de acumulação do mercado interno nacional para o espaço internacional quase sem restriçóes. Falar em liberalização e desregulação não significa dizer que não haja mediação política estatal, há que se entender o redirecionamento empreitado. O rearranjo impactou diretamente a atuação política estatal, carreando o desfazimento do amálgama político-ideológico que havia mantido a coesão da sociedade fordista.

A década de 1990 marcou a emergência de um novo cenário no tocante aos processos de integração econômica regional. Se, no fordismo, a criação de mercados regionais, paralelos às economias nacionais, não apenas embutia o fomento dos capitais mas almejava uma tentativa de convergência estrutural via políticas regionais voltadas à produção e ao crescimento, no pós-fordismo, o escopo da integraçáo ficou restrito à predominância das liberdades econômicas, deixando as preocupaçôes sociais ao sabor das alocaçôes (oscilaçôes) de recursos pelo livre mercado. $\mathrm{O}$ processo integracionista europeu, desde seu início, pelo pioneirismo, pela inovaçáo de sua proposta e, principalmente, pela sua posição central no processo de acumulação capitalista, exerceu influência sobre fenômenos análogos que pipocaram pela periferia do globo. Assim como ditou o ritmo das iniciativas no âmbito do fordismo, a guinada na experiência europeia no pós-fordismo também impactou os rumos da integração regional no mundo.

Nesse diapasão, a integração econômica adquiriu uma nova conotação. Seguindo a intensificação da internacionalização dos capitais, as iniciativas regionais se reconfiguraram como blocos econômicos, balizadas pela lógica de fomento da concorrência no âmbito internacional. A etimologia dos léxicos é bem significativa: a promoção de espaços mais uniformizados, coesos e bem definidos, de laços mais estreitos e sólidos, cujo vetor é o econômico, podendo assim resistir e sobreviver em meio à concorrência internacional. A política dos Estados nacionais não pode atrapalhar essa engrenagem técnica voltada a se impor na competição no mercado internacional. $\mathrm{Na}$ tendência à oligopolização da concorrência, uma economia nacional que não se basta isoladamente deve se aliar a outras e buscar a inserção 
regionalizada e, portanto, mais competitiva no mercado. A dinâmica concorrencial é mais restrita a algumas unidades e ainda mais acirrada.

Essa tendência impulsionada pelo pós-fordismo coaduna-se e, ao mesmo tempo, catapulta a internacionalização dos capitais. Nessa dinâmica, os blocos econômicos regionais adquirem um significado específico, próprio do contexto do pós-Guerra Fria, o que, por sua vez, altera determinantemente os rumos da integração econômica regional no sistema de Estados. Fundamental ressaltar aqui que a internacionalização dos capitais não ocorre em meio à falaciosa oposição entre Estado e mercado. Os Estados são vetores privilegiados da internacionalização dos capitais, a qual acontece por meio ou contra as políticas estatais. Os Estados e seu sistema não desaparecem, mas têm sua faceta alterada no capitalismo pós-fordista, impactando os moldes da integração econômica regional.

O sistema de Estados náo desaparece com esse desenvolvimento, mas sofre uma transformação fundamental. A tendência para a regionalização da economia mundial e para a constituição de blocos econômicos em concorrência é um momento impulsionador da internacionalizaçáo do capital. Eles obrigam as grandes empresas a fazerem-se presentes em diferentes espaços econômicos de forma simultânea e a dividir de forma correspondente seus investimentos (Hirsch, 2010, p. 182-183).

A delimitaçâo de espaços de liberdades econômicas atrai os capitais e fomenta sua valorização. $\mathrm{O}$ fortalecimento do mercado comum regional é uma forma de assentir com essa dinâmica e a agudizar a competição. A cooperação interestatal torna-se interessante, visto que permite uma aliança dos capitais nacionais e internacionais que transcende a polarização de classes dentro do território nacional. Por meio de blocos econômicos, vantagens concorrenciais comuns são garantidas no mercado mundial. Assim, os capitais deparam-se com menos obstáculos ao seu processo de valorização.

As articulaçóes entre Estados devem ser pensadas como necessidades de reprodução interna do capital e também como imperativos de sua reproduçáo internacional (...). Ao mesmo tempo, a circulação de capitais e de pessoas entre unidades políticas distintas necessita do aparato de referenciais diplomáticos comuns. Mas, além disso, a constituição dos blocos, de mercados comuns, de instituições multilaterais e internacionais permite que haja melhores condiçôes para a concorrência entre Estados e também para que o capital encontre menos obstáculos ao seu processo de valorização (Mascaro, 2013, p. 97).

Nesse arranjo, os processos de integração regional serão ainda mais fortalecidos e incentivados, constituindo uma engrenagem institucional de organização internacional repleta de regras, procedimentos e novidades normativas. A trajetória da integração regional no subcontinente insere-se dentro desse panorama, agora, porém, mais restrita ao sul, somente sul-americana e não mais latino-americana, em função da guinada do México para cima do Rio Grande. 
Assim, aproveitando a toada de equacionamento de questóes bélicas (desenvolvimento de energia nuclear) e estratégicas (hidrelétrica de Itaipu), como as desconfianças mútuas dos regimes militares, e em meio a um panorama de mudanças regionais, com a ascensão dos pleitos pela redemocratização, e internacionais, com a ofensiva ao socialismo pela defesa da modernizaçáo neoliberal, iniciativas localizadas mostram maior vigor e viabilidade, o que germina projetos, como o Mercosul e outros em seu reboque.

\section{A INTEGRAÇÃO REGIONAL SUL-AMERICANA NO PÓS-FORDISMO: DE MERCOSUL E UNASUL A PROSUL}

O Mercosul é o maior exemplo dessa fase atual. Com objetivos predominantemente comerciais, ${ }^{8}$ ou seja, de fomento ao comércio exterior na região, o bloco foi concebido após o equacionamento das rivalidades regionais entre Brasil e Argentina, agregando Uruguai e Paraguai. Os quatro governos ditos modernizantes, de inspiração neoliberal, que celebraram seu tratado constitutivo ${ }^{9}$ viam na integração regional um projeto de inserção internacional que podia fortalecer as posiçóes comerciais dos produtos locais no amplo e desregulado mercado concorrencial mundial. Essa dinâmica durou até a primeira crise mais sensível na região, a de 1999, que tragou o Brasil e, ainda mais, a Argentina, para a crise política e econômica (Kan, 2013).

Essa via exclusivamente comercial foi em grande parte reformulada no início da década de 2000. A inflexão política e econômica na América do Sul veio das desilusóes oriundas da globalização, que motivaram a chegada ao poder em quase todo o continente de forças de centro-esquerda que deslocaram os rumos do projeto para uma tendência desenvolvimentista, de foco mais amplo, com iniciativas para além de apenas o comércio exterior, como aprofundamento regiona ${ }^{10}{ }^{\mathrm{e}}$ mecanismos de financiamento. ${ }^{11}$ Ao longo dos últimos anos, o Mercosul conseguiu alcançar o estágio de união aduaneira, pretendido desde sua gestação, em função de uma tarifa

8. Os protocolos posteriores confirmam isso. Podemos citar como tratados importantes na área comercial que vieram a compor o direito primário do Mercosul, o Protocolo de Ouro Preto, de 1994; o Protocolo de Buenos Aires sobre Matéria Contratual, de 1994; o Protocolo de Fortaleza sobre Defesa da Concorrência no Mercosul, de 1996; o Protocolo de Montevidéu sobre Comércio de Serviços, de 1997; e o Acordo sobre Arbitragem Comercial Internacional do Mercosul, de 1998.

9. 0 Tratado de Assunção foi celebrado em 26 de março de 1991 por Fernando Collor de Mello, pelo Brasil, Carlos Saúl Menem, pela Argentina, Luiz Alberto Lacalle, pelo Uruguai, e por Andrés Rodríguez, pelo Paraguai.

10. Um Parlamento do Mercosul foi implementado, novos países acertaram sua adesão, como a Venezuela, em 2006 , e a Bolívia, em 2012, o sistema de solução de controvérsias foi aperfeiçoado com a entrada em vigor do Tribunal Permanente de Revisão e o com o Protocolo de Montevidéu sobre o Compromisso Democrático, de 2012.

11. Em 2006, foi constituído o Fundo de Convergência Estrutural (Focem), no âmbito do bloco, único mecanismo regional de financiamento com recursos integralmente doados por seus financiadores (o que o diferencia de outras agências regionais de fomento, como o Banco Europeu de Investimentos, por exemplo). Ainda se tem à disposição poucas linhas de crédito, muitas das quais já foram aprovadas, mas sequer entraram em vigor. A maioria delas reside em âmbito interno dos Estados, por meio de bancos nacionais de fomento, como o Banco Nacional de Desenvolvimento Econômico e Social (BNDES), no Brasil, por exemplo. há também propostas de instrumentos mais estreitos de cooperação econômica, como a monetária. 
externa comum (TEC), a qual é fonte de muitas controvérsias e exceçôes, e um código aduaneiro.

Por ser a melhor expressão da integração regional pela economia política liberal - oriunda do pós-1945, que se aprofundou após 1991 -, em meio à guinada na política exterior da região, o Mercosul conservou sua estrutura, tendo seu foco e atuação redirecionados, novamente para uma vertente mais restrita, de ênfase quase que exclusiva ao comércio exterior. $\mathrm{O}$ retorno às origens da gestação mercosulina ganha uma particularidade no momento atual diferentemente de outrora. Por enquanto, o bloco regional não é o foco da política externa brasileira para a região (no governo Fernando Henrique Cardoso o projeto era um dos focos do tabuleiro de prioridades), mesmo porque o multilateralismo não é a vertente hodierna primordial, haja vista que mesmo o espectro intermitente da Área de Livre Comércio das Américas (Alca) ${ }^{12}$ não voltou aos holofotes. O que ganha força é a estratégia bilateral - e os possíveis tratados bilaterais de livre comércio com os Estados Unidos. ${ }^{13}$

A integração regional do pós-1945 também teve efeitos na cooperação política. Para o continente americano foi traduzida de imediato a configuração aliada da guerra na OEA, de 1948, com a liderança e condução dos Estados Unidos para a região. A tradiçẫo diplomática brasileira seguiu esse movimento, combinando por anos a cooperação multilateral institucional, em um âmbito mais amplo, da OEA, e um foro mais específico, ${ }^{14} \mathrm{com}$ as coalizóes específicas quanto a assuntos pontuais. ${ }^{15} \mathrm{Em}$ maior ou menor medida, a política externa brasileira - a despeito de alguns governos (Castelo Branco, Café Filho e Fernando Henrique Cardoso) e algumas ações específicas (envio de tropas para a intervenção da OEA na República Dominicana e o apoio político à Alca) serem mais próximos de um alinhamento automático aos Estados Unidos - manteve, do pós-guerra em

12. A Alca foi uma proposta apresentada pelos Estados Unidos, em 1994, na tentativa de integrar economicamente as três porções das Américas. Seu objetivo era eliminar as barreiras tarifárias (em alguns setores) entre os 34 países envolvidos. Foi muito criticada por perpetuar a dominância estadunidense e favorecer excessivamente os produtos norte-americanos. Naufragou antes mesmo do prazo estipulado para sua conclusão. Ainda assim, é frequentemente reanimada pelos entusiastas da aproximação econômica com os Estados Unidos.

13. Em paralelo às iniciativas autônomas de integração econômica na América do Sul, criou-se a Aliança do Pacífico em 2012, formada por Colômbia, Chile, México e Peru (a Costa Rica aderiu em 2013), todos voltados para a integração econômica da América Latina, via Oceano Pacífico, com a Ásia, por meio de acordos, ou propostas, de livre comércio encaminhados com os Estados Unidos.

14. Como a articulação e criação da Organização para o Tratado de Cooperação Amazônica (OTCA), cuja pedra fundamental é do tratado multilateral de 1978, e a sua institucionalização em organização internacional, de 2002.

15. Por exemplo, o Grupo do Rio, que é uma junção de dois grupos, o da Contadora, formado, em 1983, por México, Panamá, Colômbia e Venezuela para mediar as crescentes crises políticas na América Central, em função do aumento do intervencionismo estadunidense na região; e o de Apoio a Contadora, de 1986, que contou com a adesão de Brasil, Peru, Argentina e Uruguai. Assim, originou-se o Mecanismo Permanente de Consulta e Concertação Política da América Latina e Caribe, cuja concepção vislumbrava a criação de um espaço de solução de controvérsias e de cooperação política sem a pesada influência dos Estados Unidos, como ocorria frequentemente na OEA. 
diante, uma conduta mais pragmática, na linha, com maior ou menor ênfase, da Política Externa Independente (PEI). ${ }^{16}$

A guinada à centro-esquerda na América Latina nos anos 2000 marcou um momento inédito em termos de integração regional. Para além do vetor econômico, já ancorado na economia política capitalista da época, teve impulso a cooperação política, no sentido da constituição de organizações internacionais estruturadas institucionalmente que abrissem um espaço independente de discussão das questóes locais e que, ao mesmo tempo, se contrapusesse à ordem estadunidense vigente desde a OEA. O contraponto era muito mais no plano da independência de ideias e açóes do que do confronto direto. Em muito, as iniciativas empreendidas inspiravam-se nas concepçóes de Simón Bolívar, de unidade e autonomia da região em relação ao norte do continente, que guardava franca oposição à doutrina Monroe, que pregava a todo o continente a proteção e guarida dos Estados Unidos e que foi materializada na OEA.

Nessa toada, uma postura mais autônoma foi gradativamente gestada, ${ }^{17}$ e, com o empurrão inicial da Venezuela e uma adesão muito pragmática, e menos entusiástica, do Brasil, vieram no subcontinente articulaçôes importantes como a UNASUL e até mais abrangentes, como a Comunidade de Estados Latino-Americanos e Caribenhos (CELAC). ${ }^{18}$ Nesse sentido, em 2004, no imediato momento de chegada ao poder de governos sociais-democratas na maior parte dos países, é proposta pelo governo venezuelano, capitaneado, então, por Hugo Chávez, a Comunidade Sul-Americana de Naçóes (CASA).

A iniciativa é recebida, ao mesmo tempo, com entusiasmo e desconfiança, o que a impede de decolar em um primeiro momento. As elites locais temiam uma aproximação demasiada com a Alternativa Bolivariana para as Américas

16. A PEI marcou o posicionamento da chancelaria nacional a partir de 1961, ainda no governo Jânio Quadros, que, em relação à bipolaridade mundial entre Estados Unidos e União Soviética, buscava uma atuação pragmática, voltada para a consecução dos interesses nacionais e para a autonomia brasileira, sem nenhum alinhamento automático a nenhum dos dois lados, com ampla abertura para firmar acordos com qualquer um dos blocos sempre que conveniente. Como o foco nacional era a promoção da industrialização e do desenvolvimento interno, o interesse nacional era concretizado nessa direção.

17. A iniciativa pioneira desse prisma político veio um pouco antes da ascensão dos governos de centro-esquerda, impulsionada pela desilusão quanto à ideia de mercado externo como fator de desenvolvimento, como a Integração da Infraestrutura Regional Sul-Americana (IIRSA). Proposto pelo governo brasileiro e criado em agosto de 2000, na Reunião dos Presidentes da América do Sul, em Brasília, ainda com o germe do neoliberalismo em seu embrião, 0 projeto visa coordenar grandes obras de infraestrutura do subcontinente, abrangendo, pela primeira vez, todos os seus doze países independentes. Em outras palavras, para se inserir no mercado internacional, os países sul-americanos precisariam ter uma infraestrutura mínima que facilitasse a logística e viabilizasse a competitividade de seus produtos em meio à concorrência externa. Sem canais de escoamento, com a respectiva diminuição dos custos de transporte e circulação de mercadorias, ficaria inviável a inserção externa em meio à ordem mundial do momento.

18. A CELAC é um foro ampliado de concertação política, voltado para integração e desenvolvimento. Criado em 2010, reúne os 33 países da região, inclusive com a presença de Cuba. Sua criação deveu-se, entre outros fatores, à necessidade de um mecanismo político para resolver conflitos, como a crise de Honduras, de 2010, e viabilizar consensos. 
(ALBA), ${ }^{19}$ também do mesmo ano (2004). Com uma postura conciliatória, na tentativa de uma moderação, o Brasil propóe a UNASUL, em maio de 2008, em Brasília, celebrando seu Tratado Constitutivo, fazendo emergir, assim, um foro autônomo e complementar a outros, que visa à discussão e resolução dos problemas sul-americanos por seus próprios representantes.

A organizaçáo é uma tentativa de agregar todas as iniciativas na América do Sul em torno de um mesmo centro gravitacional, reunindo todos os doze países independentes da região e sendo estruturada por um corpo institucional composto por um conselho de chefes de Estado e de governo, um conselho de ministros de relaçóes exteriores, um conselho de delegados e uma secretaria geral, bem como conselhos temáticos, envolvendo diversos assuntos, como energia; saúde; defesa; desenvolvimento social; problema mundial das drogas; educação, cultura, ciência, tecnologia e inovação; economia e finanças; e infraestrutura e planejamento. No documento foram previstos também a sede da organização, em Quito, no Equador, e os futuros parlamentos, em Cochabamba, na Bolívia, e Banco do Sul, ${ }^{20}$ em Caracas, na Venezuela.

Em torno do consenso político, vários projetos foram colocados em prática, desde uma ampla rede de financiamento para redução de assimetrias regionais ${ }^{21}$ até solução e pacificação de conflitos, como a questão anterior mas ainda latente da Media Luna, ${ }^{22}$ na Bolívia, e a crescente escalada de tensão entre Colômbia e Venezuela, ${ }^{23}$ em decorrência da instalação de bases militares estadunidenses naquele país, a qual foi apaziguada no âmbito da instituiçấo.

19. Hoje a ALBA se intitula Aliança Bolivariana para os Povos de Nossa Terra ou Tratado de Comércio dos Povos, funcionando como instrumento de cooperação regional voltada à integração social, política e econômica entre países da América Latina e do Caribe, como Cuba, Venezuela, Nicarágua, Bolívia, Antígua e Barbuda, Dominica e São Vicente e Granadinas.

20. 0 Convênio Constitutivo está vigente, desde dezembro de 2011, para Argentina, Bolívia, Equador, Uruguai e Venezuela. 0 capital inicial do banco deverá ser de US\$ 7 bilhões, para os quais Brasil, Argentina e Venezuela contribuirão igualitariamente com US\$ 2 bilhões cada; Equador e Uruguai, com US\$ 400 milhões cada; e Bolívia e Paraguai, com US\$100 milhões cada. Os recursos do banco poderão ser utilizados para financiar projetos nas áreas de infraestrutura; complementariedade produtiva intrarregional; desenvolvimento de setores sociais (saúde, educação, seguridade social, entre outros); e redução de assimetrias. A estrutura institucional do Banco do Sul compreende um conselho de ministros, um conselho de administração, um diretório executivo e um conselho de auditoria.

21. Como o mercado externo não seria a fonte de financiamento, os países buscaram os recursos necessários nas corporações regionais de fomento, como o Banco Interamericano de Desenvolvimento (BID), o Fundo Financeiro para o Desenvolvimento dos Países da Bacia do Prata (FonPlata) e a Corporação Andina de Fomento (CAF). Logo foi estabelecida uma rede de funcionamento, como uma direção executiva, um comitê de cooperação técnica e grupos de trabalho voltados para os primeiros projetos, chamados de eixos de integração e desenvolvimento (EID). Em função de sua importância, a IIRSA foi incorporada à UNASUL como secretaria técnica pelo Conselho Sul-Americano de Infraestrutura e Planejamento (Cosiplan), em 2009, o que expõe seu vínculo com a organização internacional em questão.

22. A tensão na região boliviana conhecida como Media Luna foi decorrente da postura dos governos locais em desacordo com a política do governo central, contra o qual enfrentamentos internos e atos de desobediência civil e política foram praticados. A questão colocou em xeque a unidade territorial da Bolívia, mas foi pacificada e intermediada pela UNASUL.

23. A Colômbia celebrou em 2009 um Acordo Militar com os Estados Unidos, no qual era prevista a instalação de bases militares em território colombiano sob o argumento de combate ao narcotráfico e ao terrorismo. A medida não agradou a Venezuela e nem os outros países sul-americanos. O Conselho de Defesa da UNASUL foi o palco, no qual a questão foi debatida entre seus membros, arrefecendo os ânimos. 
Colocar-se como alternativa autônoma trouxe à organização internacional muita resistência local às suas propostas. O bloco também enfrentou desafios e dilemas, como as disputas internas pela liderança interna entre Brasil e Venezuela (Pascual, 2013), bem como a crise internacional de 2008, eclodida primeiramente no seio do capitalismo para posteriormente chegar à periferia, além da resistência dos Estados Unidos ao projeto. Antes mesmo de completar uma década de existência, a UNASUL já sofreu graves solavancos políticos que emperraram seu desenvolvimento. A deposiçẫo pelo Parlamento do entấo governo paraguaio em $2012^{24}$ foi o primeiro ato de uma estratégia que viraria tônica na regiáo.

A reversão parcial da onda progressista sul-americana - e o retorno dos governos neoliberais, agora, ainda mais à direita - ocorreu tanto pela via eleitoral quanto pelo impedimento político-administrativo (impeachment). Argentina, Bolívia, Brasil, Equador, Peru, Colômbia e Chile são exemplos de mais uma inflexão na integração sul-americana. Os governos que ascenderam ao poder defendem um plataforma político-econômica de aprofundamento ao neoliberalismo, acompanhado por uma política externa muito mais associada à estadunidense, próxima a um realismo periférico. ${ }^{25}$

Assim, a UNASUL entrou em processo de esvaziamento após a negligência e até a denúncia de seu tratado por alguns países, em uma estratégia deliberada de apoiar a política estadunidense para o subcontinente e de isolar a Venezuela na região - o que se concretizou ainda mais indisfarçavelmente com o Grupo de Lima. ${ }^{26}$ Em abril de 2018, Brasil, Argentina, Chile, Colômbia, Paraguai e Peru decidiram conjuntamente suspender sua atuação na UNASUL sob o argumento de uma crise prolongada no órgão, sem perspectivas de solução. Em 2018, a Colômbia, e, em 2019, o Brasil denunciaram formalmente o Tratado Constitutivo da UNASUL, o que resulta na saída de dois importantes membros. ${ }^{27}$ Além do Grupo de Lima, a coordenação coletiva dos Estados insatisfeitos com os rumos políticos das últimas décadas culminou com a celebração de um espaço antípoda de integração.

24. A destituição do socialdemocrata Fernando Lugo do Poder Executivo ocorreu em um processo demasiadamente célere, que durou um pouco mais de 24 horas.

25. Mais informações em Guimarães (2019), Fiori (2019) e Martins (2019).

26. Grupo de Lima é a reunião de países que subscreveram a Declaração de Lima, exarada em janeiro de 2019 por meio da qual países americanos, como Argentina, Brasil, Canadá, Colômbia, Costa Rica, Guatemala, Honduras, Panamá, Paraguai, Peru e Santa Lúcia, expuseram sua insatisfação e repúdio ao que chamam de governo ilegítimo de Nicolás Maduro, na Venezuela, não reconhecendo a legitimidade do processo eleitoral de 2018 que o reelegeu. Entre sanções e restrições à Venezuela, prezam pela restauração da ordem democrática no vizinho.

27. A denúncia é um instituto próprio do direito internacional e configura ato de competência do Poder Executivo, sem a participação do Poder Legislativo, o qual, no Brasil, atua apenas no momento de incorporação interna dos tratados internacionais. Conforme o art. 24 do Tratado Constitutivo da UNASUL, a denúncia deve respeitar o prazo de seis meses para a efetivação da saída, além do pagamento de eventuais contribuições ordinárias que estiverem pendentes. 
A proposta do PROSUL foi lançada em março de 2019, após reunião em Santiago, no Chile. Presentes estavam representantes de Brasil, Argentina, Chile, Colômbia, Equador, Guiana, Paraguai e Peru, que assinaram a declaração em que indicavam a vontade de constituir o projeto. Convém destacar que Uruguai, Bolívia e Suriname declinaram sua adesão de início, e a Venezuela sequer foi convidada a participar. ${ }^{28}$ Não ficou claro de imediato como será sua operacionalidade, mesmo porque é uma declaração de intençóes e não um tratado constitutivo; o documento aponta, entretanto, para a formação de uma estrutura leve e flexível, sem uma sede determinada, com regras de funcionamento claras e um mecanismo ágil de tomada de decisôes. ${ }^{29}$ Os valores fundamentais exarados para a unidade foram a democracia e o respeito aos direitos humanos. Gradualmente, o bloco pretende ir se consolidando.

A iniciativa vai totalmente ao encontro da política externa do governo Jair Bolsonaro, convergindo diretamente com um de seus quatro pilares defendidos desde a campanha: ${ }^{30} \mathrm{o}$ redirecionamento das parcerias e das coalizóes na América do Sul, aprofundando a integração com países latino-americanos que ele considera livres de ditaduras de governos à esquerda. Nessa questão, há um claro alinhamento automático com as posiçóes externas dos Estados Unidos para a América Latina, vorazes há tempos pela derrubada e o desmonte dos governos progressistas na região (Amorim, 2019). E os governos de orientaçáo contrária são sumariamente isolados e ameaçados, como no caso da Venezuela. Fez-se necessário, entấo, um espaço político de concertação e de condução da nova política regional que substituísse a UNASUL e aglutinasse esses pleitos. Em outras palavras, que abandonasse as concepçóes de Bolívar e se aproximasse novamente da visão de Monroe para a América.

O PROSUL evidencia, portanto, a guinada atual da América do Sul rumo à direita e extrema-direita, como se pode verificar nos países envolvidos. A preocupação com a desconstrução dos pilares da integração regional tocada pelos governos anteriores é notória e amplamente defendida (Araújo, 2019). Ainda sem nenhuma medida ou mecanismo e ancorado em valores abstratos, configurando uma grande e densa bruma de incerteza, o foro inaugura um momento no Cone Sul das Américas que, por enquanto, foca apenas em rechaçar o arranjo anterior.

28. Com o golpe de Estado na Bolívia ao final de 2019 e a eleição no Uruguai, que reconduziu ao poder os liberais, pode ser que esse cenário mude. Contudo, até o presente momento não houve nenhuma manifestação de adesão dos dois países à carta de intenções de Santiago, com vistas a apoiar o Prosul.

29. Mais informações em Hoeveler (2019).

30. Os outros três pilares são: defesa da política de imigração do governo Trump; retirada do Brasil do Comitê de Direitos Humanos da ONU (órgão do Pacto de Direitos Civis e Políticos da Organização das Nações Unidas); criação de um campo de refugiados em Roraima para receber aqueles oriundos da Venezuela, com o auxílio da ONU. Mais informações em: <https://www.valor.com.br/eleicoes-2018/propostas/candidato/5>. 


\section{CONCLUSÃO}

Diante do que foi exposto, cabe por ora encerrar este artigo com algumas observaçóes que merecem destaque. A integração regional, como um processo sistemático, precisa ser contextualizada. Processos desse tipo ganham especificidade e conteúdo com o advento do capitalismo como modo de produçáo dominante no mundo e centralidade no pós-Segunda Guerra Mundial, em meio à reorganização do globo pela hegemonia estadunidense. É nesse panorama que as relaçóes de produção capitalistas chegam à América Latina e penetram fundo nos tecidos sociais das naçóes. Com o projeto comunitário da Europa Ocidental como vitrine e laboratório, desenrolam-se tentativas integracionistas por todo o mundo. A partir de entáo, as iniciativas de integraçáo regional passam a ser tomadas como uma estratégia desejada e altamente recomendável, pois seria necessariamente benéfica.

Se moldada pelo capitalismo e suas transformaçôes, a integração regional tem a economia política em sua ossatura. A especificidade é dada em um contexto próprio, primeiramente do capitalismo fordista e, posteriormente, do pós-fordista - dois momentos de inflexão, de transformação do capitalismo mundial. Ainda no pós-1945, sem espaço para políticas liberais, constrói-se no plano internacional, fora da correlação interna e nacional de classes, uma estratégia gradual - em função das circunstâncias - de formação de um mercado livre e comum, um espaço das liberdades econômicas, que aproximaria politicamente os Estados por laços econômicos - como se esse movimento não fosse completamente atravessado pela política -, em um processo quase que natural, técnico, asséptico, neutro. Durante o fordismo, mesmo a seara internacional, campo fértil para essas iniciativas, também era influenciada pelo modo de desenvolvimento do capitalismo. Ou seja, no fordismo, mesmo a integraçâo regional era pautada pela formação de livres mercados, mas com alguma intervenção de políticas públicas, no sentido de aproximação de convergências e redução de assimetrias estruturais. Tanto o projeto comunitário europeu quanto a integraçáo latino-americana, como ALALC, ALADI e seu regionalismo fechado, são exemplos dessa dinâmica.

No pós-fordismo, e o consequente desmonte das bases do fordismo, qualquer intervenção estatal no sentido de redução de assimetrias fica alijada, à margem, para o fomento quase que exclusivo das liberdades econômicas. Nesse momento, concretizam-se, ainda que parcialmente, os outrora planejados mercados comuns - e livres -, ganhando ainda mais ênfase e centralidade, como se fossem a inevitável tendência do futuro. Os projetos adquirem um corpo institucional robusto, recebendo a nomenclatura de blocos regionais - ou seja, mais coesos, interligados. Esse fenômeno ocorre a partir da guinada comunitária dada em Maastricht, da qual resulta a União Europeia, como também no nascimento do Mercosul, como exemplo mais notáveis. 
O interregno de um pouco mais de uma década da guinada à centro-esquerda na América do Sul permite que, aqui no Cone Sul, a integração seja incrementada e expandida do ponto de vista normativo e institucional, com o fortalecimento das iniciativas existentes e o surgimento de novos projetos em várias searas, como o foi a UNASUL, por exemplo. Os governos progressistas sul-americanos durante curto intervalo tentaram manejar dentro dos limites do pós-fordismo uma integração regional com maior presença de políticas públicas e ações coletivas e multilaterais. Esforço que alcançou uma arquitetura orgânica que, entretanto, foi levada de roldão pela crise econômica e a retomada do neoliberalismo na regiáo como remédio para uma crise gerada pelo próprio neoliberalismo.

O PROSUL é ilustrativo da tendência que se consolida, de ruptura clara com o período anterior e de ascensão da direita, estigmatizando e isolando os governos de espectro político progressista. Até agora, sem grandes iniciativas concretas, o bloco significa a desconstrução da ordem anterior, o que, por si só, já é sintomático, pois remete a regiâo para sua tradicional posiçâo histórica de subalternidade e dependência externa. O que havia de grande exceção na trajetória política sul-americana mais contemporânea era a articulação independente representada pela UNASUL e os governos progressistas que a levantaram. O seu abandono é suficientemente impactante.

Tomando a economia política como pano de fundo da integração regional no capitalismo que, no pós-1945, se forja no ideário liberal, podemos entender que a trajetória dos processos integracionistas contou com forte inspiraçáo ideológica na promoção das liberdades econômicas, sendo, na prática, temperada com maior ou menor dirigismo estatal. A novidade atual é a chegada ao poder de governos de direita ou de extrema-direita, anunciada pelo retorno do neoliberalismo, agora, exacerbado, que encontra no PROSUL um foro político de concertos entre Estados com a mesma orientaçáo política e de condução da nova diretriz regional de integração.

\section{REFERÊNCIAS}

AMORIM, C. Nau sem rumo: a política externa brasileira no início de 2019. Margem Esquerda, n. 32, p. 33-39, 2019.

ANDERSON, P. El nuevo viejo mundo. Madrid: Akal, 2012.

ARAÚJO, E. Os primeiros avanços da nova política externa. Valor Econômico, 8 maio 2019. Disponível em: <http://www.itamaraty.gov.br/pt-BR/discursosartigos-e-entrevistas-categoria/ministro-das-relacoes-exteriores-artigos/21003-osprimeiros-avancos-da-nova-politica-externa-valor-economico-08-05-2019>. 
BONEFELD, W. Más allá de las relaciones internacionales: acerca del mercado mundial y el estado-nación. In: KAN, J; PASCUAL, R. (Comp.). Integrados (?): debates sobre las relaciones internacionales y la integración regional latino-americana y europea. Buenos Aires: Imago Mundi, 2013. p. 43-70.

BONEFELD, W.; HOLLOWAY, J. Introduction: post-Fordism and social form. In: . (Ed.). Post-Fordism and social form: a Marxist debate on the post-Fordist state. London: Palgrave Macmillan, 1991. p. 1-7.

BRAUNMÜHL, C. On the analysis of the the bourgeois nation State within the world market context. In: HOLLOWAY, J.; PICCIOTTO, S. (Ed.). State and capital: a Marxist debate. London: Edward Arnold, 1978. p. 160-177.

FIORI, J. L. Geopolítica e fé. Carta Maior, 8 jan. 2019. Disponível em: $<$ https://www.cartamaior.com.br/?/Editoria/Poder-e-ContraPoder/Geopoliticae-Fe-/55/42882>. Acesso em: 5 jun. 2019.

GRAMSCI, A. Americanismo e fordismo. Tradução de Gabriel Bogossian. São Paulo: Hedra, 2008.

GUIMARÃES, S. P. Política externa brasileira e os cem primeiros dias de governo. Fundaçáo Perseu Abramo, 12 abr. 2019. Disponível em: <https://fpabramo. org.br/2019/04/12/politica-externa-brasileira-e-os-cem-primeiros-dias-degoverno/>. Acesso em: 5 jun. 2019.

HIRSCH, J. Teoria materialista do Estado: processos de transformação do sistema capitalista de Estados. Rio de Janeiro: Revan, 2010.

HOEVELER, R. Bolsonaro e o bailinho da direita em Santiago do Chile. Esquerda Online, 2 abr. 2019. Disponível em: <https://esquerdaonline.com. br/2019/04/02/bolsonaro-e-o-bailinho-da-direita-em-santiago-do-chile/>.

JESSOP, B. Regulation theory, post-Fordism and the state: more than a reply to Werner Bonefeld. In: BONEFELD, W.; HOLOWAY, J. (Ed.). Post-Fordism and social form: a Marxist debate on the post-Fordist state. London: Palgrave Macmillan, 1991. p. 69-91.

KAN, J. Una relación particular. Clase dominante, gobierno y orígenes del Mercosur. In: KAN, J.; PASCUAL, R. (Comp.). Integrados (?): debates sobre las relaciones internacionales y la integración regional latino-americana y europea. Buenos Aires: Imago Mundi, 2013. p. 155-204.

KURZ, R. O colapso da modernizaçáo: da derrocada do socialismo de caserna à crise da economia mundial. Tradução de Karen Elsabe Barbosa. Rio de Janeiro: Paz e Terra, 1992. 
LIPIETZ, A. Miragens e milagres: problemas da industrialização no terceiro mundo. São Paulo: Nobel, 1988.

MARTINS, C. E. O governo Bolsonaro e a dupla face de uma política externa servil. Blog da Boitempo, 20 mar. 2019. Disponível em: <https:// blogdaboitempo.com.br/2019/03/20/o-governo-bolsonaro-e-a-dupla-face-deuma-politica-externa-servil/>. Acesso em: 13 maio 2019.

MASCARO, A. L. Estado e forma política. São Paulo: Boitempo, 2013.

OSORIO, L. F. B. Um estudo crítico da Uniáo Europeia: contradiçôes de seu desenvolvimento institucional e normativo. 2015. Tese (Doutorado) Universidade Federal do Rio de Janeiro, Rio de Janeiro, 2015.

. Capitalismo e processos de integraçâo regional. Revista de Estudos Jurídicos UNESP, v. 22, n. 35, p. 13-38, jan.-jun. 2018.

PASCUAL, R. Unasur: la constitución de un soporte regional del poder soberano estatal. In: KAN, J.; PASCUAL, R. (Comp.). INTEGRADOS (?): debates sobre las relaciones internacionales y la integración regional latino-americana y europea. Buenos Aires: Imago Mundi, 2013. p. 219-250.

POULANTZAS, N. Hegemonia y dominación en el Estado moderno. Córdoba: Pasado y Presente, 1969.

\section{BIBLIOGRAFIA COMPLEMENTAR}

AGOSTINE, C.; NEUMANN, D. Eleiçốes 2018: propostas dos presidenciáveis. Valor Econômico, 17 ago. 2018. Disponível em: <https://www.valor.com.br/ eleicoes-2018/propostas/tema/15>. Acesso em: 12 maio 2019.

BANDEIRA, L. A. M. Brasil, Argentina e Estados Unidos: conflito e integração na América do Sul (da Tríplice Aliança até ao Mercosul). Rio de Janeiro: Civilização Brasileira, 2010.

OSORIO, L. F. B. A integraçáo econômica via União Europeia: liçôes para a América do Sul? Brasília: Ipea, 2016. (Texto para Discussão, n. 2219).

VASCONCELOS, R. C. de. Regionalismo, multilateralismo, o Mercosul e a OMC: o rinoceronte no Sul e a manada. Belo Horizonte: Arraes, 2017.

VIGEVANI, T.; RAMANZINI JUNIOR, H. Autonomia, integração regional e a política externa brasileira: Mercosul e UNASUL. Dados, v. 57, n. 2, p. 517-552, 2014. 
